\title{
The Relationship between Structural Dimensions of Personality and School Life in Adolescence
}

\author{
A Relação entre Dimensões Estruturais da Personalidade \\ e a Vida Escolar na Adolescência
}

\author{
Renato G. Carvalho* \& Rosa F. Novo \\ Centro de Investigação em Psicologia, Universidade de Lisboa, Lisboa, Distrito de Lisboa, Portugal
}

\begin{abstract}
In this cross-sectional study, we analyse the relationship between personality, which was operationalized in the PSY-5 dimensions of the Minnesota Multiphasic Personality Inventory - Adolescent (MMPI-A) and the way students live their lives at school, expressed through indicators of achievement, integration, and overall satisfaction. A total of 351 students, aged 14-18 years, participated in the study. The instruments were the Portuguese version of the MMPI-A and the School Life Questionnaire. Results show a pattern of significant relationships between personality traits and school life, being Disconstraint and Introversion the personality dimensions that stood out mostly in the explanation of school life variables results. Results are analysed considering the importance of personality for the development of more or less adaptive pathways in adolescence.

Keywords: Personality, adolescence, school life, MMPI-A, PSY-5 dimensions.
\end{abstract}

\begin{abstract}
Resumo
Neste estudo transversal, analisamos a relação entre a personalidade, operacionalizada nas dimensões PSY-5 do Inventário Multifásico da Personalidade de Minnesota - Adolescente (MMPI-A), e o modo como os adolescentes vivenciam o seu percurso escolar, expresso em indicadores de desempenho, integração e de satisfação global. Participaram no estudo 351 estudantes com idades entre os 14 e os 18 anos. Os instrumentos foram a versão portuguesa do MMPI-A e o Questionário sobre o Percurso Escolar. Os resultados revelam um padrão de relações significativas personalidade-vida escolar, destacando-se as dimensões da personalidade Desinibição e Introversão na explicação da maioria dos resultados das variáveis escolares. Os resultados são analisados considerando a importância da personalidade para a definição de trajetórias de desenvolvimento mais ou menos adaptativas.

Palavras-chave: Personalidade, adolescência, vida escolar, MMPI-A, dimensões PSY-5 do MMPI-A.
\end{abstract}

Understanding the reasons that make individuals behave in a certain manner and to identify the factors contributing for the explanation of (un)adaptive pathways throughout the life cycle has always been a focus of research in the individual differences domain. Especially in adolescence, where major physical and psychosocial changes occur, and a plethora of new opportunities emerge, the comprehension of the factors influencing behaviour in normative contexts, such as school, is of uttermost importance.

Adolescents spend more time in school that in any other place outside home (Eccles, 2004). It is in school where they can express their characteristics and are presented with several development opportunities, such as social interaction with peers and adults, discovery of interests,

\footnotetext{
" Mailing Address: Centro de Investigação em Psicologia, Faculdade de Psicologia, Universidade de Lisboa, Alameda da Universidade, Lisboa, Portugal 1649-013. E-mail: renatoggc@gmail.com e rfnovo@psicologia.ulisboa.pt
}

or skills acquisition and mastery. Simultaneously, the progression throughout schooling is as well demanding, since it is increasingly expected from adolescents the ability to regulate behaviour, be autonomous, and manage different tasks independently. School is therefore one of the most privileged contexts for the analysis of adolescents' developmental pathways and particularly for the understanding of the factors that influence them. That is to say, if the factors influencing the way adolescents live their life are to be understood, school context cannot be ignored.

Among the factors that are connected to adolescent development, in the present study we focus the individual characteristics at personality level, as they are potentially explicative of adolescent behaviour in their life contexts, and of the way they create and attribute meaning to experience. In fact, resulting from the interaction between innate characteristics and life experiences, and, on the other hand, being an agent that influences behaviour, personality can be considered an aggregative concept, being essential for the comprehension of adolescents' developmental pa- 
thways. Globally, we resort to Allport's (1961) definition of personality as the dynamic organisation of physical and psychological systems that are subjacent to individual patterns of action, thinking, and feeling, and that can be expressed in dimensions at different levels (vide McAdams \& Olson, 2010), namely traits or structural dimensions, characteristic adaptations, and narrative identity. In this study we focus the first level, and assess whether the way these personality structural dimensions are organised within the individual is significantly related to behaviour in school context. From a bidirectional causal nexus, it is our view that if, on the one hand, we cannot disregard that the school life contributes for personality development, on the other hand, behaviour in school context is revealing of the individual's personality.

Nevertheless, if the study of the relationship between personality and adaptation to school life is to be comprehensive, one should not ignore the complexity of school life and the fact that it involves several dimensions and not only academic performance. That is, beyond achievement related variables, school life includes a wider set of dimensions, namely indicators of integration (e.g., behaviour and relational patterns, the involvement in school extracurricular activities and adjustment to transitions), as well as adolescents' sense of accomplishment or overall satisfaction about school life. Since that all these dimensions are approached in this study, we think this research can bring a more inclusive picture concerning how relevant personality structural dimensions are for students' adaptation to school.

\section{Personality Organisation and Adaptive Behaviour in Adolescence}

Given that the present study proposes to discuss in what extent personality can be considered a relevant dimension for adolescents' adaptation to school life, it useful to mention the main conclusions of literature involving the relationship between personality traits and adaptive behaviour. This approach is especially pertinent since adolescence is a rather significant period of personality traits development and organisation. Accordingly, one of the most focused aspects in literature has been the way the expression of personality traits, such as those included in the five factor model (Costa \& McCrae, 1992), evolves during this period. Several empirical studies and literature reviews (Caspi, Roberts, \& Shiner, 2005; Donnellan, Conger, \& Burzette, 2007; Klimstra, Hale, Raaijmakers, Branje, \& Meeus, 2009; Pullmann, Raudsepp, \& Allik, 2006; Soto, John, Gosling, \& Potter, 2011) convey the idea of both stability and change in personality, as well as the association between personality characteristics and adaptive behaviour patterns throughout this developmental period. For instance, investigation shows personality maturation throughout adolescence, with increments in mean results in Affability, Openness to experience, Conscientiousness, and emotional stability, and then a trend for more stability in personality profiles in late adolescence (Klimstra et al., 2009; Pullmann et al., 2006; Soto et al., 2011). The final phase in adolescence is special relevant in the analysis of personality evolution, since there have been signalled significant modifications, which include a decline in negative emotionality and behavioural disinhibition (impulsiveness, irresponsibility, sensation seeking), and, on the other hand, an increase in characteristics related to higher Affability, Conscientiousness, and emotional stability (Caspi et al., 2005; Donnellan et al., 2007; Johnson, Hicks, McGue, \& Iacono, 2007; McAdams \& Olson, 2010). This circumstance corresponds to the propensity for individuals to show more conscious, affable, and emotionally stable, as they evolve from adolescence to adulthood - the maturity principle (Caspi et al., 2005; McAdams \& Olson, 2010; Roberts, Caspi, \& Moffitt, 2001). This propensity deserves emphasis when we put school life in perspective, as it might consubstantiate itself in higher adaptation in adolescence-adulthood transition and in the lower likelihood of risky behaviour or involvement in stress generating situations.

The relationship between personality and success in several life domains has been very emphasized, as the individual differences in the way cognition, emotion, and behaviour are integrated and regulated in adolescence has a relevant impact in individual pathways and in psychopathology development (Steinberg, 2009). Personality can therefore be a protective or risk factor, since it influences not only the exposition to potential stressors or negative stimuli, as it can as well exert influence on the way each adolescent manages them. For instance, Conscientiousness and the behavioural inhibition capacity predict low exposition to stressors and relate to lower frequencies of impulsive actions that can generate internalizing and externalizing problems (Carver \& Connor-Smith, 2010; Compas, 2004). Extraversion and Affability are as well associated to positive results in health and well-being, in part as they potentiate social relationships, social support, and integration, which by their turn are related to more favourable to health results. On the contrary, Neuroticism can be a predictor of clinical symptoms and humour perturbations, anxiety, and externalizing problems (Carver \& Connor-Smith, 2010).

\section{Personality Development in Adolescence within a Life-Cycle Perspective}

Under a developmental focus on personality in adolescence, it is unavoidable the reference to Erikson's (1968) epigenetic model of the life cycle, which describes personality development throughout a series of steps, progressing from child dependency towards a crescent individuation through internalizing, identification, and integration processes, based in the socialization system (Novo, 2003). In Erikson's perspective, adolescence corresponds to a crucial period for personality development, especially in the individual's creation of a sense of singularity and continuity. Erikson's model constitutes 
the first theory that includes the entire life course within a developmental perspective and becomes precursor of dialectical developmental models (Blatt, 1990; Blatt \& Blass, 1990), which give a central relevance not only to individuation processes, but as well to relationship tasks. Based on Erikson's model, Blatt (1990) tries to go beyond what he names a one-dimensional conception of development, which values mostly self-identity, and highlights the importance of the self-in-relationship for development. In Blatt's perspective, "development results from a complex interaction between two personality lines through dialectic, cumulative, and integrative processes" (Novo, 2003, p. 168): on one hand, the capacity to establish satisfactory interpersonal relationships (relatedness), and, on the other hand, the capacity to establish an essentially positive and integrated self-concept.

Within this dialectic framework, adolescence is essential for the integration of these two personality developmental dimensions, a task that will convey the perception of the self as an independent identity. Integration is therefore crucial in adolescence, and difficulties in this integration can lead to feelings of low personal value and lack of life meaning. On the contrary, a sufficient integration in adolescence, and after during adulthood, creates a psychological context that allows individual a coordinated development and a mature expression of him/her individuality and inter-relationship. (Novo, 2003, p. 183)

In sum, having as a background the development in adolescence, in this study we analyse the relationship between personality structural dimensions and the way adolescents live their life at school, which is expressed not only in achievement or performance, but as well in indicators of social integration and satisfaction. It is our goal to comprehend in what extent the way personality is organising in adolescence is related to adolescents' behaviour at school, and particularly, which personality dimensions are more prominent in that relationship. Given that literature has been focusing mostly the influence of personality in school grades, this study contributes to further clarification of the real importance of personality in school life, by including a wider range of school life variables.

\section{Method}

\section{Participants}

Participants were 351 ninth to twelfth grade Portuguese students (212 girls, about 60\%) attending compulsory school, high school, and professional training courses in several public schools in the region o Madeira, Portugal. Students' majority was living in rural areas (about 64\%) and their ages varied between 14 and 18 years $\left(M_{\mathrm{Age}}=16\right.$; $S D=1.43$ ). A significant relationship Age $\mathrm{x}$ School level was found, $\chi_{(20, N=351)}^{2}=223.27, p<.001$, with a superior than expected number of older students for the level they were in. This is related to the fact that approximately $50 \%$ of the students had at least one retention in the school pathway. Almost half of the students $(n=167)$ had both parents with mandatory school completed (and/or at least one of the parents had completed secondary education). Only a small minority of the students had both parents with a college degree $(n=21)$. The remaining students had both parents with qualifications inferior to the present mandatory school $(n=87)$ or both parents with secondary education $(n=75)$. Given that parents' qualifications are a relevant indicator for sociocultural or socioeconomic status (SES), we can consider the sample as being predominantly constituted with students from medium-low SES families (Carvalho \& Novo, 2012).

\section{Measures}

School Life Questionnaire (SLQ; Carvalho \& Novo, 2010). This self-report questionnaire collected data from several school life dimensions, which we present next. School achievement involved the perception of school performance and success, and was assessed through 8 items (Cronbach's $\alpha=.74$ ) such as "I've been having good grades" or "I've been studying to get good grades". Adaptation to school transitions corresponded to the degree in which the year and school changes were evaluated as successful, with 6 items $(\alpha=.84)$ such as "I've experienced difficulties when changing school" or "Normally, I've adapted myself easily when changing the school year". Other dimensions were the frequencies of behaviour problems (10 items; $\alpha=.85)$, mostly related to indiscipline (e.g., "I've had disciplinary sanctions in my school path", "I have been reprimanded for breaking the rules"), and of risk behaviours (11 items; $\alpha=.76$ ), namely substance use, risky sexual behaviour or eating problems (e.g., "I've consumed a great amount of alcohol in a short period of time", "I've already smoked tobacco", "I've had unprotected sexual relationships"). The interpersonal difficulties domain (11 items; $\alpha=.74$ ) involved not only interpersonal conflicts (e.g., "I've had problems in the relationship with teachers", "I've had conflicts with colleagues") but as well social withdrawal and perception of lack of social support (e.g., "I don't have many friends at school"; "I've had the support of my family to deal with school issues"). Participation in extracurricular activities was assessed through 7 items ( $\alpha=.74)$, for example "I've been participating in school clubs, projects or other extracurricular activities" or "I've had the opportunity to put in practice my talents beyond the school classes". Finally, we also assessed adolescents' overall satisfaction about school life (9 items; $\alpha=.75$ ), that is, a global sentiment, a sense of accomplishment or a balance about school life (e.g., "I'm satisfied with my school pathway so far", "If I could go back in time, I'd change many things in my school pathway"). We considered the simple mean of each variable items, so the higher the mean, the more applicable to the student their content is.

Minnesota Multiphasic Personality Inventory-Adolescent (MMPI-A; Butcher et al., 1992). We assessed ado- 
lescent personality through the Portuguese experimental version of the MMPI-A (Silva, Novo, Prazeres, \& Pires, 2006), a 478 item self-report questionnaire. In this study, we resorted to MMPI-A PSY-5 dimensions (McNulty, Harkness, Ben-Porath, \& Williams, 1997), a descriptive and dimensional model of personality, based on a conceptual system of five main factors, and characterised by an emphasis on personality traits, rather than on psychopathology dimensions. We mention next these five dimensions, as well as their number of items and the Cronbach's alfas obtained with this sample results. Aggressiveness (20 itens; Cronbach's $\alpha=.73$ ) reflects a tendency for anger and hostile and combative behaviour, with an emphasis on instrumental and offensive aggressiveness. It also involves feelings of grandiosity and desire for power or social dominance. Psychoticism (21 items; $\alpha=.73$ ) involves the contact with reality and the accuracy of cognitive models about the world, which are created by the individual, as well as unusual sensorial and perceptive phenomena, and interpersonal suspiciousness. Disconstraint (24 items; $\alpha$ $=.72$ ) is related to risk propensity, tendency for impulsive actions, self-control difficulties, non-traditional morality and noncompliance or difficulties in following rules. Neuroticism (22 items; $\alpha=.74$ ) corresponds to an affective disposition to experience negative emotions, such as anxiety, nervousness, feelings of guilt and preoccupation, all of them leading to internal suffering. Finally, Introver$\operatorname{sion}(22$ items; $\alpha=.74$ ) reflects low drive and low positive emotionality, as well as a global tendency to dislike and to not seek social experiences, which causes social withdrawal, alienation, and poor communication.

\section{Procedures}

After the official authorisations and informed consent assurance, instruments were administered in two sessions and in class context, in several middle and high schools during May and June, 2010. SLQ was administered firstly and MMPI-A (paper and pencil version) in the second session. MMPI-A protocols were read optically and data transferred to a SPSS database, which was thereafter completed with SLQ results. Before being used in the study, protocols were evaluated, concerning their validity and response consistency. There wasn't previously identified any case of psychopathology within the sample.

Design and Analysis. The testing of relationships between variables was performed through Pearson correlations, after confirmation of normality, linearity, and homoscedasticity assumptions. Through stepwise models, multiple linear regressions were implemented to predict each school life variable results according to PSY-5 dimensions. For each model we inserted all PSY5 dimensions, and selected those presenting significant effects in the stepwise regression model. We verified previously the assumptions of normality, homoscedasticity, and error independence through Durbin-Watson statistics and graphically. Although the selection of variables was performed through stepwise models, we also resorted to VIF in order to identify potential multicollinearity problems.

Hypothesis. Assuming that personality development and adolescents' school life integration are connected, our general hypothesis was that higher results in PSY-5 dimensions tend to be related with poorer academic performance, more integration difficulties, and less satisfaction with the school life. This general hypothesis derives from the idea that the characteristics subjacent to PSY-5 dimensions are reflected or condition, even though indirectly, adolescent behaviour in several life contexts, so individual differences in those dimensions will associate to differences as well in adolescent integration in those contexts. When defining specific hypothesis we considered literature results that convey an association between personality and different behaviour patterns. Among these results, we withdraw attention to the association between less consciousness, impulsivity, and lack of affability, on the one hand, and several unfavourable indicators of performance, interpersonal difficulties, and behaviour problems, on the other (Caspi \& Shiner, 2006; Poropat, 2009; Singh \& Waldman, 2010; van Aken \& Dubas, 2004; Zuckerman \& Kuhlman, 2000). Although most of these studies refer to Big Five personality traits, we can consider them related to PSY dimensions, since they involve similar behaviours and characteristics (Friedman, Lewak, Nichols, \& Webb, 2001). Therefore we considered the following specific hypotheses:

1. h1. Adolescents presenting higher Disconstraint indexes have poorer academic performance, are less satisfied with the school life, and tend to present unfavourable indicators of school life integration (ie, higher frequencies of behaviour problems, risk behaviours, and interpersonal difficulties).

2. h2. Aggressiveness is related to higher frequencies of behaviour problems and interpersonal difficulties in school context.

3. h3. Introversion is related to higher frequencies of interpersonal difficulties and school transitions problems, and to a less frequent participation in extracurricular activities.

4. h4. Higher results in Psychoticism relate to more frequent interpersonal difficulties.

5. h5. Adolescents presenting higher indexes of Neuroticism have more difficulties in adapting to school transitions and are less satisfied with school life.

\section{Results}

The pattern of correlations, most of them significant to moderate (Cohen, 1988), shows an association between personality and the school life variables, which corroborates the view that personality differences are related to distinct behaviour patterns in school context. Several personality dimensions, with Disconstraint being the more relevant, are associated to most school variables, a pattern that reveals their importance for behaviour in school. We 
also highlight Introversion, which is the only personality dimension significantly associated to extracurricular activities, a result that underlines the importance of positive emotionality characteristics for the participation in school activities. We present in Table 1 the Pearson correlation coefficients.

Table 1

Pearson Correlation Coefficients between PSY-5 Dimensions and School Life Variables, for Each Sex

\begin{tabular}{llllll}
\hline Girls & AGGR & PSYC & DISC & NEGE & INTR \\
School Achievement & $-.259^{* *}$ & $-.202^{* *}$ & $-.264^{* *}$ & $-.170^{*}$ & $-.197^{* *}$ \\
School Transitions & -.089 & -.115 & -.088 & $-.169^{*}$ & $-.215^{* *}$ \\
Behaviour Problems & $.423^{* *}$ & $.262^{* *}$ & $.474^{* *}$ & $.164^{*}$ & -.062 \\
Risk Behaviours & $.327^{* *}$ & $.317^{* *}$ & $.472^{* *}$ & $.286^{* *}$ & .014 \\
Interpersonal Difficulties & $.275^{* *}$ & $.299^{* *}$ & $.171^{*}$ & $.206^{* *}$ & $.325^{* *}$ \\
Extracurricular Activities & -.013 & .074 & -.067 & -.044 & $-.302^{* *}$ \\
School Life Satisfaction & $-.391^{* *}$ & $-.258^{* *}$ & $-.357^{* *}$ & $-.280^{* *}$ & $-.256^{* *}$ \\
\hline Boys & AGGR & PSYC & DISC & NEGE & INTR \\
School Achievement & $-.279^{* *}$ & $-.320^{* *}$ & $-.348^{* *}$ & $-.249^{* *}$ & $-.228^{* *}$ \\
School Transitions & -.132 & $-.203^{*}$ & .030 & $-.211^{*}$ & .001 \\
Behaviour Problems & $.354^{* *}$ & $.190^{*}$ & $.478^{* *}$ & .114 & .028 \\
Risk Behaviours & .056 & .097 & $.384^{* *}$ & .000 & -.021 \\
Interpersonal Difficulties & $.314^{* *}$ & $.399^{* *}$ & $.180^{*}$ & $.289^{* *}$ & $.261^{* *}$ \\
Extracurricular Activities & -.160 & -.166 & -.134 & -.092 & $-.247^{* *}$ \\
School Life Satisfaction & $-.232^{* *}$ & $-.349^{* *}$ & $-.349^{* *}$ & $-.270^{* *}$ & $-.283^{* *}$ \\
\hline
\end{tabular}

Note. AGG - Aggressiveness; PSYC - Psychoticism; DISC - Disconstraint; NEGE - Neuroticism; INTR - Introversion. $* p<.05 ; * * p .01$.

Regression results, which are presented in Table 2, illustrate significant prediction models of school life results, as a function of personality dimensions. Concerning satisfaction with the school life, Aggressiveness, Introversion, and Disconstraint were significant predictors for girls, $F_{(3.208)}=21.33, p<.001, R^{2}=.24$, and Disconstraint, Psychoticism, and Introversion for boys, $F_{(3,135)}=13.64$, $p<.001, R^{2}=.23$. These results suggest that more aggressive, introverted, and social distanced adolescents, as well as those who have impulse control difficulties, are less satisfied with their school life and do a negative balance of it.

Regarding the indicators of school life integration, we note that personality is relevant in the explanation of the variability of behaviour problems and of risk behaviours. In girls, Disconstraint and Aggressiveness are significant in predicting behaviour problems, $F_{(2,209)}=35.12, p<.001$, $R^{2}=.25$, whereas in boys, Disconstraint can contribute by itself to an appreciable percentage of variability, $F_{(1,137)}=$ $40.59, p<.001, R^{2}=.23$. Same tendency is observed in risk behaviours, in which Disconstraint and Neuroticism appear as relevant to girls' results, $F_{(2,209)}=35.36, p<.001$, $R^{2}=.25$, and Disconstraint to boys' results, $F_{(1,137)}=23.74$, $p<.001, R^{2}=.15$. Pertaining interpersonal difficulties, it is possible to obtain a parsimonious model in which Introversion and Aggressiveness are predictors for girls, $F_{(2.209)}=22.59, p<.001, R^{2}=.18$, and Psychoticism and Introversion are significant predictors for boys, $F_{(2,136)}=$ $16.31, p<.001, R^{2}=.19$.

In the case of the participation in extracurricular activities, one should mention the relevance of Introversion, Psychoticism, and Disconstraint in girls, $F_{(3,208)}=$ $10.72, p<.001, R^{2}=.13$, and Introversion in boys, $F_{(1,137)}$ $=8.90, p=.003, R^{2}=.06$. These results emphasize the social dimension importance in extracurricular activities, whether considering the relevance of individual social skills to participate in them, or the context of interpersonal relationships they involve. There are also obtained significant models for school transitions, in which Introversion is a significant predictor in girls, $F_{(1,210)}=$ $10.21, p=.002, R^{2}=.05$, and Neuroticism is a significant predictor in boys, $F_{(1,137)}=6.38, p<.001, R^{2}=.05$. Despite de reduced percentage of explained variability, results indicate that sociability and positive emotionality are related to school transitions, whereas negative emotionality contributes to difficulties in changes throughout schooling. Finally, concerning school achievement, we verify once more the importance of Disconstraint and Introversion for 
the explanation of girls' results, $F_{(2,209)}=12.44, p<.001, R^{2}$ $=.11$, and the importance of Disconstraint, Psychoticism, and Introversion for boys' results, $F_{(3,135)}=11.18, p<$
$.001, R^{2}=.20$. Again, the models lay emphasis on selfregulation, high drive, and positive emotionality, and on the school path social dimension.

Table 2

Regression Coefficients of School Path Variables on PSY-5 Personality Dimensions, for Each Sex

\begin{tabular}{|c|c|c|c|c|c|}
\hline Criterion variable & Sex & Predictor & $B$ & $S E$ & $\beta$ \\
\hline \multirow[t]{6}{*}{ School Life Satisfaction } & \multirow[t]{3}{*}{$\mathrm{F}$} & Aggressiveness & -.04 & .01 & $-.27 * * *$ \\
\hline & & Introversion & -.03 & .01 & $-.23 * * *$ \\
\hline & & Disconstraint & -.03 & .01 & $-.18 *$ \\
\hline & \multirow[t]{3}{*}{ M } & Disconstraint & -.05 & .02 & $-.26 * * *$ \\
\hline & & Psychoticism & -.04 & .01 & $-.23 * *$ \\
\hline & & Introversion & -.04 & .01 & $-.21 * *$ \\
\hline \multirow[t]{5}{*}{ School Achievement } & \multirow[t]{2}{*}{$\mathrm{F}$} & Disconstraint & -.05 & .01 & $-.26 * * *$ \\
\hline & & Introversion & -.03 & .01 & $-.19 * *$ \\
\hline & \multirow[t]{3}{*}{$\mathrm{M}$} & Disconstraint & -.04 & .01 & $-.27 * * *$ \\
\hline & & Psychoticism & -.03 & .01 & $-.21 * *$ \\
\hline & & Introversion & -.02 & .01 & $-.16^{*}$ \\
\hline \multirow[t]{2}{*}{ School Transitions } & $\mathrm{F}$ & Introversion & -.05 & .01 & $-.24 * *$ \\
\hline & $\mathrm{M}$ & Neuroticism & -.04 & .02 & $-.21 *$ \\
\hline \multirow[t]{3}{*}{ Behaviour Problems } & \multirow[t]{2}{*}{$\mathrm{F}$} & Disconstraint & .04 & .01 & $.35 * * *$ \\
\hline & & Aggressiveness & .02 & .01 & $.21 * *$ \\
\hline & $\mathrm{M}$ & Disconstraint & .07 & .01 & $.48 * * *$ \\
\hline \multirow[t]{3}{*}{ Risk Behaviours } & \multirow[t]{2}{*}{$\mathrm{F}$} & Disconstraint & .05 & .01 & $.43 * * *$ \\
\hline & & Neuroticism & .02 & .01 & $.18 * *$ \\
\hline & $\mathrm{M}$ & Disconstraint & .05 & .01 & $.38 * * *$ \\
\hline \multirow[t]{4}{*}{ Interpersonal Difficulties } & \multirow[t]{2}{*}{$\mathrm{F}$} & Introversion & .04 & .01 & $.32 * * *$ \\
\hline & & Aggressiveness & .03 & .01 & $.27 * * *$ \\
\hline & \multirow[t]{2}{*}{$\mathrm{M}$} & Psychoticism & .05 & .01 & $.36 * * *$ \\
\hline & & Introversion & .03 & .01 & $.19 *$ \\
\hline \multirow[t]{4}{*}{ Extracurricular Activities } & \multirow[t]{3}{*}{$\mathrm{F}$} & Introversion & -.08 & .02 & $-.35 * * *$ \\
\hline & & Psychoticism & .08 & .03 & $.23 * *$ \\
\hline & & Disconstraint & -.05 & .02 & $-.17 *$ \\
\hline & $\mathrm{M}$ & Introversion & -.07 & .02 & $-.25 * *$ \\
\hline
\end{tabular}

$* p<.05 ; * * p<.01 ; * * * p<.001$.

\section{Discussion}

In this study we analysed the pattern of relationships between personality factors and the way adolescents deal with school life challenges. Results confirm the global hypothesis that personality is related to school life in adolescence, and particularly that the way personality is organising in adolescence can be considered an important indicator of adaptation to school. Specifically, differences in personality associate to variances in the way each individual relates to others, in the likelihood of problem or risk behaviours engagement, and even in the way he/her deals with the schooling related changes.

The pattern of results confirms then the specific hypotheses of this study, though in some cases the hypotheses were confirmed only for one gender, and in other cases 
the extension of the personality influence was superior to what we predicted. Thus, we have found that Disconstraint associates to a wide set of indicators of higher school life integration difficulties (h1) and that Aggressiveness is related to more frequent behaviour problems and interpersonal difficulties in school context (h2). Concerning h3, we obtained confirmation for the relationship between Introversion and interpersonal difficulties and less participation in extracurricular activities. However, concerning adaptation to school transitions, the hypothesis was only confirmed for girls. Moreover, Introversion also associated significantly to school life overall satisfaction. Regarding $\mathrm{h} 4$, Psychoticism was related to interpersonal difficulties, as predicted, with the results expressing as well a significant association with that PSY-5 dimension and boys' satisfaction with school life, and with girls' participation in extracurricular activities. Finally, we had confirmation for $\mathrm{h} 5$, with results illustrating a wider array of significant relationships, since Neuroticism was associated to many school life variables.

We consider that these results contribute to a comprehensive picture in this research domain, whose focus has frequently targeted mostly the relationship between personality and academic performance, expressed in grades. In fact, if there's a great amount of data showing the relevance of personality factors in the prediction of academic performance (Poropat, 2009), we could now observe that personality has an extensive relationship to other school life dimensions, such as interpersonal relationships, behaviour problems, risk behaviours, school transitions or even the participation in extracurricular activities, although with different amounts of explained variability. Among the PSY-5 dimensions that were more notable in the explanation of adolescent behaviour, that is, that were present in most regression models, we emphasize Disconstraint and Introversion. The pattern of results suggests that, on the one hand, self-regulation capacity and, on the other, positive emotionality, interest in social experiences, and high drive are important features for adolescents' integration into school life. In our view, these outcomes highlight the mention of several theoretical models to the integration of internal and relational dimensions for adolescents' adaptation, that is, the integration of emotional-behavioural organisation and relatedness to the construction of satisfactory pathways in adolescence (e.g., Blatt, 1990; Novo, 2003).

Considering the sphere of possibilities that adolescence comprises and the consequent requirements of self-regulation capacities, commitment to personal goals, and management of relationships with others (Steinberg, 2009), the characteristics that underlie personality dimensions such as Disconstraint and Introversion are fundamental for the success with which adolescents manage developmental tasks of this life period. This idea is supported by the results of other studies that included structural personality models, in which Conscientiousness - whose characteristics are inserted within an analysis framework near Disconstraint (in reverse sense) - is the dimension that presents stronger and stable relationships with several indicators of school achievement (Poropat, 2009).

On the other hand, we cannot ignore the importance of considering several school life domains for adolescents' well-being. In fact, the life pathway construction, especially in school context, involves a more comprehensive idea of success and adaptation, that not only includes academic achievement, but as well the satisfaction and subjective perception of achievement, individual behaviour patterns, interpersonal relationships, the participation in school activities, and the way each student adapts to schooling related changes. Among the school life variables, we highlight the overall satisfaction about the school life, which was significantly associated to all PSY-5 dimensions, a result that indicates that personality plays a prominent role in students' overall assessment and balance about school life. This pattern was repeated in regard to school achievement, which comprises students' assessment of their academic performance, expressed in grades and involvement and commitment to study. There were also found significant relationships between personality dimensions and behaviour at school, which supports literature, for instance concerning behaviour problems (e.g., Hill, 2002; Joyce \& Oakland, 2005; Miller \& Lynam, 2001), risk behaviours (e.g., Hoyle, Fejfar, \& Miller, 2000; Rolison \& Scherman, 2002; Vollrath, Knoch, \& Cassano, 1999; Vollrath \& Torgersen, 2008), or interpersonal difficulties (e.g., Caspi \& Shiner, 2006).

In sum, this study results emphasize the relevance of personality for adolescents' behaviour at school, not only considering achievement or academic performance but as well taking into account the complexity of variables that characterise school context. We can consider, hence, that if the different adolescent pathways are to be understood, personality variables should be considered.

\section{Implications for Theory and Practice}

In our view, the results of this study emphasize the need for considering the role that personality differences have in school context, beyond aptitudes or cognitive abilities. In fact, the study outcomes sustain the proposals that point out the necessity of personality inclusion in a prominent place in theories about academic success and not only some sort of "appendix" to intelligence (Poropat, 2009). Actually, many professionals in the area of education recognise a reality in which several students have cognitive potential but, for idiosyncratic reasons, do not invest in study and learning, nor are committed with school integration or with the engagement in healthy behaviour patterns. The example of Disconstraint related characteristics illustrates this assumption - although a student may have cognitive abilities, the significant presence of characteristics that are agglutinated in that personality dimension correspond to a risk factor for school success and integration. Moreover, the results consistency for this personality dimension, especially when associated to Introversion, supports the 
idea that adolescent adaptation in different life contexts is related to an evolution in personality in the sense of higher self-regulation capacities, less disinhibition, and positive emotionality (Caspi et al., 2005; Donnellan et al., 2007; Johnson et al., 2007; McAdams \& Olson, 2010; Steinberg, 2005, 2007, 2009).

Considering practice in psychological and counselling services, we confirmed that behaviour patterns relate to idiosyncratic characteristics at personality level, which can and should be identified though reliable psychological assessment techniques and leading to adequate monitoring and interventions. Considering the present and future impacts of behaviour patterns in different developmental periods, these strategies will be useful for the identification of risk signals and, consequently, for the identification of potential intervention strategies in order to promote or compensate the effects of personality characteristics. In fact, personality assessment can be useful for obtaining a wider picture about how behaviour disruptions occur, improving the identification and understanding of students at risk, especially when they may pass unnoticed within school contexts. We emphasize the early detection of behaviour patterns and characteristics that may be considered problematic and that put adolescents in vulnerability situations, which aren't always easily identifiable. The referring of adolescents at risk or exhibiting disruptions indicators may allow the implementation of psychological and educational intervention programs, having in mind the prevention of disruptive pathways. For instance, adolescents presenting accentuated behaviour regulation problems and impulsiveness may benefit from interventions involving self-control, self-monitoring, and the orientation towards goals achievement, so the negative evolution of those characteristics can in some extent be prevented. They may also receive more attention at school guidance and monitoring levels, as well as be involved in more structured educational environments. In the same sense, adolescents with high indexes of social discomfort or introversion, besides being in higher vulnerability for instance in school transitions, may benefit from intervention strategies that allow them to be more integrated in the school community and relate to others, especially when they pass unnoticed, since their problems have an internalizing nature. In last resort, students' educational and activities programs could receive some adjustments or be selected according to their idiosyncratic characteristics (Poropat, 2009) and the school organisational and disciplinary practices be more sustained and informed.

Limitations and Perspectives for Future Research

We consider the main limitations of this study correspond to the fact this is a cross-sectional, non-longitudinal study, and that data collection was performed only through self-report measures. Future investigation should take these aspects into account, for instance by resorting to more varied data collection techniques and by studying samples longitudinally. As Rutter (2005) puts it, longitudinal studies are important to the understanding of developmental mechanisms and to the analysis of the role that different variables have through time. Moreover, the exploratory nature of this study encourages in our view future research involving the specific processes through which personality exerts its effect in behaviour and adaption to school and other life contexts. This sort of studies would contribute decisively to the understanding of the mechanisms through which personality causes behaviour, that is, more explicative and non-descriptive analysis (Lynam \& Miller, 2004).

\section{References}

Blatt, S. J. (1990). Interpersonal relatedness and self-definition: Two primary configurations and their implications for psychopathology and psychotherapy. In J. L. Singer (Ed.), Repression and dissociation: Implications for personality theory, psychopathology, and health (pp. 299-335). Chicago, IL: University of Chicago Press.

Blatt, S. J., \& Blass, R. B. (1990). Attachment and separateness: A dialectical model of the products and processes of development throughout in the life cycle. Psychoanalitic Study of the Child, 45, 107-127.

Butcher, J. N., Williams, C. L., Graham, J. R., Archer, R. P., Tellegen, A., Ben-Porath, Y. S., \& Kaemmer, B. (1992). Minnesota Multiphasic Personality Inventory - Adolescent (MMPI-A): Manual for administration, scoring, and interpretation. Minneapolis, MN: University of Minnesota Press.

Carvalho, R. G., \& Novo, R. F. (2010). Questionário sobre o Percurso Escolar. Lisboa, Portugal: Faculdade de Psicologia, Universidade de Lisboa.

Carvalho, R. G., \& Novo, R. F. (2012). Family socioeconomic status and students adaptation to school life: Looking beyond grades. Electronic Journal of Research in Educational Psychology, 10(3), 1209-1222.

Carver, C. S., \& Connor-Smith, J. (2010). Personality and coping. Annual Review of Psychology, 61, 679-704.

Caspi, A., Roberts, B. W., \& Shiner, R. L. (2005). Personality development: Stability and change. Annual Review of Psychology, 56, 453-484.

Caspi, A., \& Shiner, R. L. (2006). Personality development. In N. Eisenberg (Ed.), Handbook of child psychology: Vol. 3. Social, emotional, and personality development (pp. 300-365). New York: Wiley.

Cohen, J. (1988). Statistical power analysis for the behavioral sciences. Hillsdale, NJ: Erlbaum.

Compas, B. E. (2004). Processes of risk and resilience during adolescence. In R. M. Lerner \& L. Steinberg (Eds.), Handbook of adolescent psychology ( $2^{\text {nd }}$ ed., pp. 263-297). Hoboken, NJ: John Wiley \& Sons.

Costa, P. T., Jr., \& McCrae, R. R. (1992). Revised NEO Personality Inventory (NEO-PI-R) and NEO Five-Factor Inventory (NEO-FFI): Professional manual. Odessa, FL: Psychological Assessment Resources.

Donnellan, M. B., Conger, R. D., \& Burzette, R. (2007). Personality development from late adolescence to young adulthood: Differential stability, normative maturity, and evidence for the maturity-stability hypothesis. Journal of Personality, $75(2), 237-263$

Eccles, J. S. (2004). Schools, academic motivation, and stage-environment fit. In R. M. Lerner \& L. Steinberg (Eds.), Handbook of adolescent psychology ( $2^{\text {nd }}$ ed., pp. 125-154). Hoboken, NJ: John Wiley \& Sons. 
Erikson, E. H. (1968). Identity: Youth and crisis. New York: Norton.

Friedman, A. F., Lewak, R., Nichols, D. S., \& Webb, J. T. (2001). Psychological assessment with the MMPI-2. Mahwah, NJ: Lawrence Erlbaum.

Hill, J. (2002). Biological, psychological and social processes in the conduct disorders. Journal of Child Psychology and Psychiatry, 43(1), 133-164.

Hoyle, R. H., Fejfar, M. C., \& Miller, J. D. (2000). Personality and sexual risk taking: A quantitative review. Journal of Personality, 68(6), 1203-1231.

Johnson, W., Hicks, B. M., McGue, M., \& Iacono, W. G. (2007). Most of the girls are alright, but some aren't: Personality trajectory groups from ages 14 to 24 and some associations with outcomes. Journal of Personality and Social Psychology, 93(2), 266-284.

Joyce, D., \& Oakland, T. (2005). Temperament differences among children with conduct disorder and oppositional defiant disorder. The California School Psychologist, 10, 125-136.

Klimstra, T. A., Hale, W. W., III, Raaijmakers, Q. A. W., Branje, S. J. T., \& Meeus, W. H. J. (2009). Maturation of personality in adolescence. Journal of Personality and Social Psychology, 96(4), 898-912.

Lynam, D. R., \& Miller, J. D. (2004). Personality pathways to impulsive behavior and their relations to deviance: Results from three samples. Journal of Quantitative Criminology, 20(4), 319-341.

McAdams, D. P., \& Olson, B. D. (2010). Personality development: Continuity and change over the life course. Annual Review of Psychology, 61, 517-542.

McNulty, J. L., Harkness, A. R., Ben-Porath, Y. S., \& Williams, C. L. (1997). Assessing the personality psychopathology five (PSY-5) in adolescents: New MMPI-A scales. Psychological Assessment, 9(3), 250-259.

Miller, J. D., \& Lynam, D. (2001). Structural models of personality and their relation to antisocial behavior: A meta-analytic review. Criminology, 39(4), 765-798.

Novo, R. F. (2003). Para além da eudaimonia - Bem estar psicológico em mulheres adultas com idade avançada. Lisboa, Portugal: Fundação Calouste Gulbenkian.

Poropat, A. E. (2009). A meta-analysis of the five-factor model of personality and academic performance. Psychological Bulletin, 135(2), 322-338.

Pullmann, H., Raudsepp, L., \& Allik, J. (2006). Stability and change in adolescent's personality: A longitudinal study. European Journal of Personality, 20, 447-459.

Roberts, B. W., Caspi, A., \& Moffitt, T. E. (2001). The kids are alright: Growth and stability in personality development from adolescence to adulthood. Journal of Personality and Social Psychology, 81, 670-683.

Rolison, M. R., \& Scherman, A. (2002). Factors influencing adolescent decisions to engage in risk-taking behavior. Adolescence, 37(147), 585-596.

Rutter, M. (2005). Multiple meanings of a developmental perspective on psychopathology. European Journal of Developmental Psychology, 2(3), 221-252.

Silva, D., Novo, R., Prazeres, N., \& Pires, R. (2006). Inventário Multifásico da Personalidade de Minnesota - Adolescente: Versão experimental portuguesa. Lisboa, Portugal: Faculdade de Psicologia, Universidade de Lisboa.

Singh, A. L., \& Waldman, I. D. (2010). The etiology of associations between negative emotionality and childhood externalizing disorders. Journal of Abnormal Psychology, $119(2), 376-388$.
Soto, C. J., John, O. P., Gosling, S. D., \& Potter, J. (2011). Age differences in personality traits from 10 to 65 : Big five domains and facets in a large cross-sectional sample. Journal of Personality and Social Psychology, 100(2), 330-348.

Steinberg, L. (2005). Cognitive and affective development in adolescence. Trends in Cognitive Science, 9(2), 69-74.

Steinberg, L. (2007). Risk taking in adolescence: New perspectives from brain and behavioral science. Current Directions in Psychological Science, 16(2), 55-59.

Steinberg, L. (2009). Should the science of adolescent brain development inform public policy? American Psychologist, 64(8), 739-750.

van Aken, M. A. G., \& Dubas, J. S. (2004). Personality type, social relationships, and problem behaviour in adolescence. $E u$ ropean Journal of Developmental Psychology, 1(4), 331-348.

Vollrath, M., Knoch, D., \& Cassano, L. (1999). Personality, risky health behaviour, and perceived susceptibility to health risks. European Journal of Personality, 13, 39-50.

Vollrath, M. E., \& Torgersen, S. (2008). Personality types and risky health behaviors in Norwegian students. Scandinavian Journal of Psychology, 49, 287-292.

Zuckerman, M., \& Kuhlman, D. M. (2000). Personality and risktaking: Common biosocial factors. Journal of Personality, 68(6), 999-1029. 